\title{
Compatibility Between Archival Processing of Born Digital Records and the Training of Archivists in the $21^{\text {st }}$ Century
}

\author{
Peter Pavel KLASinC, Ph.D., Assist. Prof. \\ archival councillor, Director of the International Institute for Archival Science IIAS Trieste/Maribor, Head of the \\ Archives and Records Management Studies Departmentat Alma Mater Europaea - European Centre Maribor \\ e-mail: peter.klasinc@guest.arnes.si
}

\section{Opening thoughts}

Nowadays, new relationships and needs are arising together with a certain compatibility - related to the latter - between archival processing and born-digital records, on the one hand, and the training of archivists that deal with them or will in the future, on the other. In this paper I will try to analyse the results coming from some comparisons and situations that have occurred and still occur in archival theory and practice. We certainly recall the times when we started to bring computers into the archives. Many years ago, I myself addressed this issue besides some other fellow archivists and shared my point of view in an article entitled "Working with computers in archives and archival services" (1988), where I drew attention to and gave full account of all the possibilities that we had back in the days in relation to the introduction of computers in professional archival work. Ten years later, I prepared another article bearing the title "New technologies, new media and archival material usage" (1998). At that time, and later on, many similar scientific papers were published, many conferences were organised and their proceedings were published in Sodobni arhivi, Atlanti, ICA's publications and in a number of archival journals from America, Canada, Australia and, of course, Europe.

Lots of these papers are now ancient history as far as the archival field is concerned. Nevertheless, they represent a specific stage in the evolution of concepts and solutions related to digital archiving, as they introduced new information technologies and the related terminology. At that time, this was mainly explained to us by IT specialists, while we archivists simply kept adding new entries and harmonising them to the existing vocabulary used in archival theory and practice and, more in general, in archival science. We all recall having dealt with issues regarding how to prepare and fill out entry documents, set up a coding system and solve problems deriving from new tasks associated to the introduction of information systems in archival arrangement.

Over time, solutions and problems have been even more at the forefront and we ourselves witnessed the fact that archivists, without IT specialists, would not be able to overcome a whole series of difficulties associated with born-digital archives. And it took time before IT experts came to a similar conclusion. Presenting them the evaluation and selection processes of archival and document resources with the creators, and the development of the so-called digital archives (@a.g.), equals to say that cooperation is possible. Theoretically, this is subject to the pertinent laws as well as to technical and operative solutions, but in reality this is less the case. Nowadays, there is an extremely vast literature on computer science, information technologies and the related archival tasks. I suggest that archivists, especially the younger ones, get acquainted with it!

I have to say that contemporary archival theory and practice can only develop by relying on scientific research projects and other research work based on compatible exchanges and taking into account archival and computer science knowledge and experience.

It has come the time that we rightfully refer to as information age and age of the new media and of diverse forms of communication. The gradual introduction of information technologies and related softwares comes, however, at a cost, which is why some IT specialists suggest to maximise the utilisation of the already existing information technologies. This can happen by replacing data printed on paper with equivalent electronic records, as well as by providing high-quality "online" access to archive information 
(fonds, inventories) and to data contained in archival material (full-text view). Any project regarding creators' electronic/digital filing should be grounded in a well-structured context, including the possibility to transfer such material to professional archives and to enable its professional management and longterm use.

It is true, though, that the use of archival records currently performed without particular problems by archives appears to be unproblematic. However, this is mainly due to the fact that most of those records are preserved in traditional formats and accompanied by dedicated informative material.

Several archivists acknowledge the changes imposed by both information technology and the development and storage of digital archival records in professional archives and, more or less intensely, they bring such changes in archival theory and practice.

As many decades ago some of us archivists foresaw the current situation, and even planned the introduction of new information technologies and systems in archival theory and practice, we certainly could not have imagined that in such a short period of time it would come to the acknowledgement and, in many archives, even to the implementation of the General International Standard Archival Description - ISAD $(G)$ and of the International Standard Archival Authority Record for Corporate Bodies, Persons and Families - ISAAR-CPF, as well as of all the standards deriving from the latter, including the OAIS reference model and many others.

The vast specialised archival literature, both Slovenian and international, suggests that this issue is nowadays being tackled by ever more archivists who will choose IT specialists as partners for their research projects. We can generally refer to archival papers as serious scientific research works and studies that, along with some terminology- and translation-related dilemmas, provide us with theoretical experiences and interpretations of the above-mentioned standards for professional archival work.

Some of these scientific papers, by the way, already report on archivists' practical experiences related to the implementation of the above-mentioned standards in the framework of their archival arrangement tasks.

\section{Born digital archival records}

For many years now, the classical, traditional definitions of what constitutes archival material in theory and practice have established that next to the classical, traditional media, as well as to graphic, video and audio files, some "undefined" archival material is also generated with the creators. In this regard there is no difference whatsoever as to the document format or the medium on which information is recorded. Thus, born-digital archival records are also the result of an evaluation process of specific categories related to documental material. In the past, we archivists used to establish together with the creators, and by means of special provisions, what constituted archival material, while more recently this is all in principle arranged according to classification plans, content-related instructions and, of course, technical ones. Some differences in archival inventory do clearly exist, but the information systems used to manage this kind of documents must be such to grant the most desirable evaluation, transfer, professional treatment and preservation of born-digital archival records, so that they can be used also after having been transferred to professional archives as written cultural heritage, protected by the law and recognised as a cultural asset.

Several provisions and specific paragraphs of laws on archives anyhow establish the need for born-digital records to be transferred to professional archives in a standardised format and, in some cases, even equipped with the relevant computer programme. This creates the conditions for the formation of fonds and collections in a single archive, as well as for the development of methods for their professional treatment; it also provides a baseline to understand and use several user interfaces and the prerequisite for the organisation of and unhindered access to information of archival value.

Support to such processes is mainly to be found also in archival specialised literature, where there is no difference between the definition of traditional archival material and that of digital archival material. What is important is that the material is of great relevance to science and culture in light of its content or of the information contained in it, regardless of it being on a classic or digital medium format. 
Anyway, I am not totally sure that in contemporary archival theory and practice we are already proficient in every process related to digital records, since we are still dealing with identifying the creators and evaluating the material, as well as with various forms of computer processing, with software usability and the research of the best solutions for long-term storage and utilisation of born-digital records. Moreover, many processes concerning the management of archival material in native digital format are difficult to implement due to the archives' different backgrounds and the worldwide status of archival theory and practice.

For this reason we have to take a multifaceted approach when engaging in scientific research and studies on born-digital records. Let us focus exclusively on forms and ways to evaluate information of archival value, on problems relating to the contextualisation of transferred archival material, on ways to ensure the trustworthiness of such records and so on. The fact is that some professional archives are already receiving digital records in their repositories, where these are already being used, too. In this context, many problems arise. Let us focus exclusively on problems relating to archival terminology, methods and ways to describe archival items and other problems associated with the management of technical processes involved in archival arrangement due to contemporary forms of archival material. Time and again, we archivists draw attention to the fact that information systems and technologies are subject to frequent change. This, of course, does not have to prevent us from using them, since they can provide us with an optimal quantity of information of archival value, as well as with access to the associated contextual data, individual records and their storage location, and also enable us to use specific records' information for future decision-making and support to wider information systems.

With the help of IT specialists, we archivists can set up information systems for managing archives and documents. The current legislation on protection of the latter establishes that the creators of archival records, even of the ones born in digital format, have to follow the technical guidelines laid down by the territorially competent professional archives, mostly with regard to archive protection, maintenance, selection, arrangement and preservation or restoration, as well as enable a thorough view of the material itself. Naturally, this poses the question of how many archivists, nowadays, have the skills needed to give answers in this respect.

\section{The training of archivists in the $21^{\text {th }}$ century}

The tradition of archival education and training in Europe and worldwide has long-standing roots. This is particularly evident in the development and status of available systems to gain knowledge in the field of archival science and records management.

The current status of education can be described as fairly good, since on the one hand there are faculties of archival science operating autonomously within universities or academies, while on the other hand archival studies are confined to faculty departments or academic programmes with only some hours of archival science included in other subjects, mostly history, computer science, humanities and others alike.

Archival studies, as a new scientific discipline, offer new knowledge and new paths to achieve certain objectives. Besides examining single documents, engaging in archival studies means investigating the structures of archival units, as well as their history, creation and manifestation in specific records. We establish the causes according to which some documents become part of archives, and the procedures used in the process.

Archival science teaches the principles according to which archival records are arranged in a way that allows single archival units to maintain their original order (principle of provenance).

Thus, archival studies are not merely intended to gain knowledge on archival material, but also to address all areas of archival theory and practice, with no compromises whatsoever.

By means of a special archival training we have to allow and offer any chance to acquire all possible knowledge, even specific, in this field. This includes: fundamental concepts of archival science; description of archives according to their three definitions; archival records; definitions of archival science; archival science and auxiliary sciences of history; fundamental principles of archival work; basic features of archival work, its various types and components; archival science and office management; type and deve- 
lopment of systems related to the original order; general concepts on archival records arrangement; concepts about archival records, their purpose, structure, development and selection; development and implementation of the principles of provenance of the fonds; principle of original order; organisation, arrangement and documentation of the work process while arranging archives; arrangement technique; spaces intended for selection activities and their equipment; special tasks in the arrangement process of physical units; indication of the reference number; selection operations; inventories of fonds and collections; guides and briefs; registering activities out of the archive premises; records on work with fonds; historical accounts of fonds; protection of archival records before their transfer to an archive; transfer procedures; implementation of various transfer modes; ways to monitor the protection of archival records before their transfer; private archival material, its use and access; taxes, fees and other charges relating to the use of archival records; records of loans and returns of archival material from and to the repository; professional archival tasks; microfilms; special types of records; digitised archival material; born-digital archival records; prints, maps, photographies, various copies and other records; bibliographies of Slovene and international manuals; Slovene and international journals; international standards; terminology; other.

According to a study carried out years ago by prof. Miroslav Novak, such a course would require 55 subjects if carried out at academic level. The first-cycle degree programme derived from the Bologna process (three years, six semesters) requires 25 subjects in order to hold the title of graduate archivist. Personally, I do not see the need to add anything else to archival training in the 21 th century a part from fundamentals of records management, computer science, IT equipment and electronic filing.

Archival studies must be intended for anyone who wants to acquire basic and advanced knowledge on archival and records processing and management. They must offer new and complementary knowledge that can be used in the framework of archival professional work in professional archives and in archival services with the creators of archival and documentary material. After completion of their studies, graduate archivists have to be capable to operate autonomously and master documents in the most diverse information systems.

Such studies must be provided also in light of increasingly required new knowledge on problems that arise in relation to archival and records processing in compliance with archival provisions, regulations and ordinances, as well as with domestic and international standards.

Contemporary archival studies must encourage a different kind of decision-making, more sustainable and responsible, which is essential to mastery in processing archival and documentary material, regardless of its format.

Archival studies must offer knowledge that is necessary to master the processing of archival and documentary material from its creation to its long-term storage (also electronic) and filing with the creators or professional archival institutions, passing through the phases of usage, evaluation, deposit and protection. Such knowledge is necessary given the different systems and processes involved in records management as a whole, since it also sets the baseline for the effective processing of records and the implementation of all kinds of archival long-term retention.

Archival studies must prepare the candidates to the most demanding technical and coordinating tasks with archives and archival services that deal with records retention and archival management, as well as with similar institutions involved in collecting, retaining and forwarding information. Moreover, they must promote interdisciplinary integration of archival issues and flexible use of knowledge in practice, as well as the capability to organise and plan records management processes, be acquainted with and understand the creators' institutional frameworks and work in an ambitious, creative and independent way with the institutions where they will be dealing with aspects related to archival and records management.

Archival studies must prepare the candidates to: be proficient in oral and written communication with the users of archival and documentary material; be adaptable and capable to both advise the users about advanced research settings and use the information technologies of the most widespread computer programs and communication technologies; successfully manage any kind of problem related to archival theory and practice, as well as to archival and computer science and records management; monitor document flows; take decisions about the records' final destination; understand the processes involved in 
long-term retention (also electronic) and those regarding the access to information contained in the records.

My remark may be a little too harsh, yet I do not sense any particular enthusiasm on part of archivists and IT specialists with regard to vocational training in the field of archival and computer science.

Archivists gain at the workplace the general knowledge needed for computer-supported professional archival work or, alternatively, they attend more or less intensive dedicated courses. In general, they are satisfied with the acquired knowledge, but under no circumstances is this sufficient. It is certainly true that problems with computers are constantly solved in archives, and this happens in a number of ways. Cooperation with IT specialists is of course at the first place. Many specialised archivists are good computer and archival experts - it is just a pity that their technical skills are frequently directed at solving unnecessary mistakes made by their colleagues, sometimes even at identifying the external causes of some virus attack, which raises numerous concerns.

Along with the above mentioned, we have to change over and over again the deeply rooted ideas of what constitutes archival professional work and the strong link between the latter, on the one hand, and history and auxiliary sciences of history, on the other. In the future, such connection will be ever weaker, although it will never break, as proved by everyday practice, since archival professional work more and more resorts to the principles of information sciences. In the future, it will be necessary to integrate the programmes of archival training in light of born-digital records, anyway this will not affect the core of the training itself, which will remain unaltered.

\section{Conclusions}

With reference to the compatibility between archival processing of born-digital records and the training of archivists, I will mention here some issues that will require more attention in the future.

1. How we are supposed to harmonise the knowledge on information systems for records management with the know-how and experiences gained by archivists who operate in professional archives.

2. How archivists are supposed to view a 30-year old digital record with the creator. Because of being stored on diverse media with diverse computer programs, such material is actually hardly acessible or not accessible at all.

3. How to enable access to archival material, lists, records, guides, summary or analytical inventories, protocol registers, indexes and others alike once they are on digital format - if they are not already.

4. How to enable the smooth use of born-digital archival records for scientific, cultural and other purposes with the creators as well as later, after the records are relocated to professional archives, which are indisputably responsible for the transfer of such records, but only in agreement with the creators and on the basis of an ad hoc contract or report on the transfer of the records themselves.

5. How to persuade the interested and specialised public that archival science will develop and establish itself only if we have qualified and well-trained archivists, that is to say, archivists with graduate, post-graduate or doctorate degrees.

To conclude my considerations, let me mention two Latin sayings:

Theoria sine praxis, sicut rota sine axis.

Quidquid agis, prudenter agas et respice finem. 